\title{
Latin American Society for Pediatric Research (LASPR) Selected Abstracts from the LIV Annual Meeting
}

\author{
Encarnación, Paraguay \\ October 9-12, 2016 \\ Susana Sanchez (Paraguay), President \\ Paulo Cáceres Guido (Argentina), President Elect \\ Gerardo Weisstaub (Chile), General Secretary \\ Sponsorship Statement
}

The publication of the selected meeting abstracts was funded by the Latin American Society for Pediatric Research to promote development across disciplines and to improve pediatric care in the region (www.slaip.org).

doi:10.1038/pr.2016.269

NUTRITIONAL STATUS AND NUTRITIONAL RISK AT HOSPITAL ADMISSION Arce $L^{1}$, Brennan V, ${ }^{1}$ Garcés $L^{1}$, Aello $\mathrm{G}^{1}$, Videla $J^{1}$, Rios $J^{1}$, Arnulphi $\mathrm{S}^{1}$, Weisstaub G ${ }^{2}$ 'Hospital Humberto Nottti, Mendoza, Argentina; ${ }^{2}$ Instituto de Nutrición y Tecnología de los Alimentos, Universidad de Chile

Background: Malnutrition or undernourishment when entering the hospital is a cause of risk of negative evolution in pediatric patients. The screening of nutritional risk on admission may constitute a useful tool to detect patients that require early intervention. For the first time in the hospital, a study was done to carry out a nutritional screening.

Objective: To learn about the frequency of malnutrition and undernourishment as well as the nutritional risk at hospital admission, through a sample of pediatric patients.

Methods: A random sample was taken, chosen from patients in Hospital Notti (Mendoza, Argentina). After signing an informed consent by parents or guardians, all the individuals were weighed and measured naked, by members of the research team, (previous standardization) at hospital admission and discharge. A nutritional screening was applied (Strong Kids) in the first 48 hours of the admission. Nutritional status and risk were assessed with the applied tools. For the statistical analysis, Fisher Test and Student test were used. The following work was approved by the Committee for Education, Training and Research Hospital Humberto Notti.

Results: 134 patients were admitted (59\% women), 4 months of age, (1 to 9 months) (medium sized and IQR), and hospitalization lasted 4 days ( 3 to 7 days). $31 \%$ of the patients were younger than a year and $50 \%$ of them were hospitalized due to respiratory or gastroenterological pathologies. There were not significant differences in IMC-z at the admission among the groups of higher and lower nutritional risk. On admission, $17 \%$ presented acute malnutrition, and $60 \%$ presented moderate nutritional risk. Those who suffered from high nutritional risk, went through more frequent pain change of weight, less eating, diarrhea, and signs of undernourishment, than those who suffered from moderated nutritional risk. (Fisher $<0.0001$ ).

Conclusion: Malnutrition or undernourishment at hospital admission affects about the $20 \%$ of patients and more than half presents moderated nutritional risk. These two observations justify the systematic carrying out of an evaluation of the nutritional status.

\section{2}

PREDICTORS OF MORTALITY IN CHILDREN UNDER 15 YEARS OLD WHO ACQUIRED HIV FROM MOTHER TO CHILD TRANSMISSION IN PARAGUAY

Aguilar $\mathrm{G}^{1,2,3}$, Miranda $\mathrm{AE}^{2}$ Samudio T $\mathrm{T}^{3}$, Kawabata A ${ }^{1}$, Muñoz $\mathrm{S}^{4}$, Galeano $\mathrm{F}^{\mathrm{F}}$

'Universidad Nacional de Caaguazu, Paraguay; ${ }^{2}$ Universidade Federal Do Espirito Santo (UFES), Brazil; ${ }^{3}$ National Program of HIV/AIDS, Asunción, Paraguay ${ }^{4}$ Universidad de la Frontera-Facultad de Medicina, Temuco, Chile; ${ }^{5}$ Instituto de Medicina Tropical, Asuncion, Paraguay Background: Paraguay has made efforts to improve the response to HIV infection. It is important to assess the impact of interventions in pediatrics.

Objective: To estimate predictors of mortality in children who acquired HIV from mother to child transmission (between January 2000 and December 2014).

Methods: It was about a birth cohort study among the persons living with HIV infection (PLWH) they were $<15$ years of age at enrollment. We abstracted data from clinic records, using a standardized form. We obtained the data of death from clinic records and confirmations of deaths from death certificates. We used survival analysis techniques to estimate the incidence of death.

Results: 302 subjects were included in the survey. $71.4 \%$ younger than six years of age, $51.0 \% \mathrm{fe}-$ male, $74.3 \%$ were from the metropolitan area. There were 52 deaths (17.2\% of participants), resulting in an overall mortality rate of 1.86 deaths 100 person-years [ $95 \%$ confidence interval (CI) 1.39 , 2.44]. The Children with baseline HIV viral load $>100,000$ copies $/ \mathrm{mL}$ had four times more probabilities to die than children with baseline HIV viral load $\leq 100.000$ (HR, 4.47; 95\% CI, 1.79, 11.10). Regarding age-stratified staging of disease, children with stage 3 had four times more probabilities to die compared to children on Stage ( 1 and 2) (HR, 4,.19;95\% CI, 1,50,11,70), children with hemoglobin level $\leq 9 \mathrm{~g} / \mathrm{dL}$ at baseline have four time more probabilities to die compared to hemoglobin level $\geq 9 \mathrm{~g} / \mathrm{dL}$ (HR, 3.90; 95\% CI1.61, 9.80).

Conclusion: The mortality of children with HIV in Paraguay is low. High HIV viral load, late stage and moderate or severe anemia at first diagnosis time, are associated with mortality. Improving prenatal care and pediatric follow-up in an effort to diagnose vertically infected children as early as possible should be an integrated part of the healthcare provided to the child with AIDS, and is very important as an action that may increase survival possibilities to these children.

3

THE LINK BETWEEN ACADEMIC OUTCOMES AND NUTRITIONAL QUALITY OF SNACKS IN HIGH SCHOOL IN CHILEAN ADOLESCENTS

Correa-Burrows $\mathrm{P}^{1}$, Rodríguez $\mathrm{Y}^{1}$, Blanco E2 , Gahagan $\mathrm{S}^{2}$, Burrows $\mathrm{R}^{1}$

${ }^{1}$ Institute of Nutrition and Food Technology, University of Chile. Santiago, Chile. ${ }^{2}$ Child Development and Community Health Division, University of California San Diego, USA.

Background: Snacking at school results from choices made by adolescents with little parental control. Excessive consumption of saturated fats and simple carbohydrates in the form of snacks is common among adolescents. These macronutrients have been related to impairment in hippocampal dependent learning and memory processes. Chronic exposure to high fat/high sugar snacks may compromise educational outcomes.

Objective: To study the connection between nutritional quality of school snacks and academic results of high school (HS) students in Santiago, Chile.

Methods: In a sample of 67816 year-old, we measured nutritional quality of school snacking using a validated food frequency questionnaire. Snacks were rated: unhealthy, fair or healthy based on saturated fat, fiber, sugar and salt content. Academic results included HS diploma, taking collegeadmission exams, and standardized HS grade-point average (GPA). To examine the association of nutritional quality of school snacking with academic results we performed logistic regressions and ANCOVA, after controlling sex, weight status, physical activity level, and parental education. Results: The quality of school snacks was healthy in $27 \%$ of participants. Mean GPA were 494, 508 and 529 points in unhealthy, fair and healthy snacks, respectively. Of those who completed HS $(84 \%), 68 \%$ took the exams for college admission. After controlling other influences, the odds of HS completion (OR: $0.48 ; 95 \%$ CI: $0.26-0.85$ ) and taking college entrance exams (OR: $0.54 ; 95 \%$ CI: $0.33-0.88$ ) were significantly lower among participants who ate unhealthy snacks compared to those who ate healthy snacks. Unhealthy snacks had significantly lower GPA compared to participants who ate healthy snack foods, mean grade difference 34.8 points $(95 \%$ CI: $-54.8 ;-14.9 ; d=0.44)$. Conclusion: Poorer nutritional quality of school snacks was associated with lower academic results in the transition from secondary to higher education. These results confirm earlier studies in industrialized countries, however, results from non-industrialized countries are still needed. Funding: NHBLI-HL088530 and PAI-79140003.

C-REACTIVE PROTEIN REFERENCE INTERVALS FOR VERY PRETERM NEWBORNS DURING THE NEONATAL PERIOD

Araujo $\mathrm{A}^{1}$, Capra $\mathrm{R}^{1}$, Canello $\mathrm{P}^{1}$, Cerutti $\mathrm{M}^{1}$, Cuestas $\mathrm{ME}^{1}$, Cuestas E

${ }^{1}$ Universidad de Córdoba, Argentina

Background: CRP is a powerful marker for inflammatory processes used for diagnostic and monitoring purposes. There is still no study designed exclusively to establish CRP reference values for very preterm newborns (VPN)

Objective: For this reason, we aimed to establish postnatal age specific CRP reference intervals in a representative sample of uncomplicated VPN and describe the changes in plasma CRP levels during the neonatal period. 
Methods: The data are from a cohort of infants born at Hospital Privado Universitario de Córdoba from 2010 to 2015. Inclusion criteria were: uncomplicated VPN with gestational age $\leq 30$ weeks, birth weight $\leq 1500 \mathrm{~g}$, who received consecutive blood examinations on day $0 \pm 1,3 \pm 1,7 \pm 1$, $14 \pm 1$ and day $28 \pm 1$ of life. Exclusion criteria were great malformations, death before day 28 of life, neonatal sepsis, maternal fever, chroriamnionitis necrotizing enter colitis, bleeding, shock, intraventricular hemorrhage, multiple gestation, small for gestational age, perinatal distress and patent ductus arteriosus. To calculate the predicted CRP log values, the values of postnatal age in days were inserted into a polynomial regression equation. The 2.5 and 97.5 limits were calculated as the mean predicted value plus-minus two standard deviations of the residuals.

Results: 117 VPN fulfilled the inclusion criteria. The CRP means were $0.24(0.06-0.85) \mathrm{mg} / \mathrm{dl}$ at the $1^{\text {st }}$ day, increasing to a peak of $0.27(0.06-0.91) \mathrm{mg} / \mathrm{dl}$ at the $3^{\text {rd }}$ day, and continually decreasing to $0.26(0.06-0.085), 0.16(0.06-0.52)$ and $0.11(0.06-0.38) \mathrm{mg} / \mathrm{dl}$ at the $7^{\text {th }}, 14^{\text {th }}$ and $28^{\text {th }}$ days of life. Conclusion: Uncomplicated VPN show very low CRP plasma levels, which gradually decrease during the first 28 days of life. Further studies are required to validate our findings and to determine their diagnostic and prognostic utility.

\section{5}

VITAMIN A CONTENT IN MATURE BREAST MILK. IS IT SUFFICIENT TO MEET THE NUTRITIONAL NEEDS OF BREASTFED INFANTS?

Matamoros $\mathrm{N}^{1}$, Ferrari $\mathrm{G}^{1}$, Falivene $\mathrm{M}^{1}$, Disalvo $\mathrm{L}^{1}$, Varea $\mathrm{A}^{1}$, Fasano $\mathrm{V}^{1}$, Visentin $\mathrm{S}^{1}$, Capecce $\mathrm{F}^{1}$, Gonzalez $\mathrm{HF}^{1}$

${ }^{1}$ IDIP - Instituto de Desarrollo e Investigaciones Pediátricas, La Plata, Argentina

Background: Breastfeeding is considered the ideal food because it provides the necessary nutrient for healthy growth and development. The risk of maternal vitamin A deficiency during lactation is high, particularly in developing countries. Thus, vitamin A content in milk could be insufficient to cover the recommended nutritional intake.

Objective: to assess the concentration of vitamin A in mature breast milk and determine whether such concentration meets the needs of breastfeeding infants.

Methods: We carried out an observational and cross-sectional study, analyzing milk samples obtained from mothers attending the maternal consulting room of IDIP between days 30 and 90 after delivery in the period 2012-2013. We assessed vitamin A concentration by ultra-fast liquid chromatography (UFLC) and determined whether it covered the recommendations for infants according to the Dietary Reference Intakes ( $400 \mu \mathrm{g}$ vitamin A/day up to 6 months of age). Variables were expressed as median (IQR). Spearman's coefficient was used to determine the correlation between variables. The study protocol was approved by IDIP's Institutional Research Review Board.

Results: The study included 70 mothers. Median age was 25 years (20-30) and median vitamin A concentration in milk was $51.5 \mu \mathrm{g} / \mathrm{dL}(39.0-65.8)$. The average time of lactation was 57 days (33-70). We did not find a significant correlation between time of lactation and vitamin A content. In 50\% of samples, vitamin A content did not meet the nutritional needs of breastfeeding infants.

Conclusion: Mean vitamin A concentration in milk was $51.5 \mu \mathrm{g} / \mathrm{dl}$. Although maternal milk is the best reference for infant feeding, our results showed that vitamin A content in half of the samples was not sufficient to meet the infant nutritional requirements.

\section{6}

NUTRITIONAL PROFILE OF PREGNANT ADOLESCENTS WHO ATTEND TO PUBLIC HEALTH SERVICES OF PARAGUAY

Masi $\mathrm{C}^{1}$, Sánchez Bernal $\mathrm{S}^{1}$, Morínigo $\mathrm{G}^{1}$, Zelada $\mathrm{J}^{1}$, Irazusta $\mathrm{J}^{1}$, Mendoza L

${ }^{1}$ Instituto Nacional de Alimentación y Nutrición-INAN. Ministerio de Salud Pública y Bienestar Social, Paraguay

Background: Pregnancy during adolescence involves an important nutritional risk for mothers and their newborns, situation that becomes more critical by the presence of malnutrition or micronutrient deficiency.

Objective: To describe the nutritional profile according to anthropometric data and the presence of anemia of 15 to 19 years old pregnant adolescents who attend to public health services of Paraguay. Methods: Cross-sectional study. Anthropometric data of 15 to 19 years old pregnant adolescents collected in 2015 from the Food and Nutrition Surveillance System (SISVAN) in public health services of 18 Sanitary Regions were analyzed. Nutritional diagnosis was performed according to Rosso-Mardones weight gain graphic (Am J Clin Nutr 1985). The presence of anemia was determined by the hemoglobin values reported by the health services considering WHO/UNICEF/UNU criteria

Results: 2.208 pregnant adolescents were included, the average age was $17.4 \pm 1,3$ years old; $58.2 \%$ lived in urban areas $(n=1284)$ and $78 \%$ were in a couple relationship; $43.8 \%(n=966)$ were un derweight, $10.2 \%$ were overweight and $14.5 \%$ were obese. Underweight was higher in rural areas $\left(47.2 \%\right.$ vs $\left.41.3 \% ; \div^{2} \mathrm{p}<0.05\right)$ and obesity in urban areas $\left(17.5 \%\right.$ vs $\left.10.3 \% \div \div^{2} \mathrm{p}<0.05\right)$. The median hemoglobin value was $11.8 \mathrm{~g} / \mathrm{dL}(6.5 \mathrm{a} 14.3 \mathrm{~g} / \mathrm{dL})$ and was similar in rural and urban areas (11.7 vs $11.8 \mathrm{~g} / \mathrm{dL}$; Mann-Whitney, $\mathrm{p}=0.15)$. The prevalence of anemia was $17.7 \%(\mathrm{n}=391)$ according to hemoglobin values $(<11 \mathrm{~g} / \mathrm{dL})$, and it was similar in urban and rural area $(17.3 \%$ urban area vs $18 \%$ rural area, $\left.\div^{2} \mathrm{p}=0.6\right)$. The presence of anemia was associated with underweight $(20.1 \mathrm{vs} 15.9 \%, \div 2$ $\mathrm{p}=0.01)$.

Conclusion: Prevalence of underweight in pregnant adolescents is high, especially in rural areas. Although the prevalence of anemia is mild, it is increased in underweight pregnant adolescents. This critical situation should be taken into consideration to improve maternal and child health.

\section{7}

FIRST 1000 DAYS OF LIFE FACTORS ASSOCIATED WITH AN ASTHMA PHENOTYPE: BRISA COHORT, BRAZIL

Nascimento $\mathrm{I}^{1}$; Ribeiro $\mathrm{C}^{1}$; Batista $\mathrm{R}^{1}$; de Britto e Alves $\mathrm{MT}^{1}$; Simões $\mathrm{V}^{1}$; Padilha $\mathrm{L}^{1}$; Barbieri $\mathrm{MA}^{2}$; Bettiol H²; Vianna E2; Silva $\mathrm{AA}^{1}$; Cardoso $\mathrm{V}^{2}$

${ }^{1}$ Universidade Federal do Maranhão (UFMA), São Luís, Maranhão, Brasil; ${ }^{2}$ Faculdade de Medicina de Ribeirão Preto, Universidade de São Paulo (FMRP-USP), Ribeirão Preto, Brasil
Background: Certain environmental factors present before conception and during the first 1000 days of life affect childhood asthma.

Objective: To analyze environmental factors in the first 1,000 days of life that are associated with an "asthma phenotype" in childhood.

Methods: A prospective study used data from the prenatal period, birth, and second year of life of the BRISA Cohort, São Luís, Brazil $(\mathrm{n}=1,150)$. An "asthma phenotype" was evaluated based on a medical diagnosis of asthma, number of wheezing episodes, emergency care visit due to wheezing, and medical diagnosis of rhinitis. Based on a theoretical model that included prenatal factors (socioeconomic status, pregestational body mass index -BMI-, soft drink and junk food consumption), birth factors (gestational age, birth weight, and type of delivery), and second year of life factors (breastfeeding and BMI z-scores) structural equation modeling was performed.

Results: The "asthma phenotype" was a good construct consisting of four indicators with factor loadings greater than $0.5(\mathrm{p}<0.001)$. A high prepregnancy BMI (standardized coefficient $-\mathrm{sc}-=$ $0.118 ; \mathrm{p}=0.021)$, high consumption of soft drinks during pregnancy $(\mathrm{sc}=0.117 ; \mathrm{p}=0.042)$, and caesarean section without labor $(\mathrm{sc}=0.146 ; \mathrm{p}=0.021)$ were associated with higher values of "asthmatic phenotype". In contrast, high birth weight $(s c=-0.173 ; p=0.003)$ and exclusive breastfeeding for 6 months ( $s c=-0.146 ; p=0.017$ ) were associated with lower values of "asthmatic phenotype". Conclusion: The present findings support the hypothesis that childhood asthma appears to be defined early, and environmental factors that are present before conception and during the first 1000 days of life are contributing factors to an asthma phenotype.

FLUID INTAKE PATTERNS: AN EPIDEMIOLOGICAL STUDY AMONG CHILDREN AND ADOLESCENTS ENROLLED IN SCHOOL IN PARAGUAY

Sanabria $\mathrm{M}^{1}$, Aguilar $\mathrm{G}^{2}$, Sanabria $\mathrm{G}^{2}$, Kawabata ${ }^{2}$ A, Estigarribia $\mathrm{G}^{2}$, Rolón R, Rios $\mathrm{P}^{2}$, Munoz $\mathrm{S}^{3}$, Feferbaum R $\mathrm{R}^{4}$.

${ }^{1}$ Universidad Nacional de Asunción. ${ }^{2}$ Universidad Nacional de Caaguazú. ${ }^{3}$ Universidad de la Frontera, Chile. ${ }^{4}$ Universidad de Sao Paulo, Brasil.

Background: Obesity is a multifactorial disorder, one strategy to reduce it implies the reduction of energetic intake from sugars added to children's diet. Investigators in Brazil and Argentina reported an increase in the consumption of sugared drinks in the pediatric population. There are no previous studies in Paraguay about the pattern of consumption of these beverages in children. Objective: To evaluate the pattern of consumption of energetic beverages in children and adolescents enrolled in schools in Asunción, Caaguazú and Central, and the association of malnutrition due of excess of the same.

Methods: We used a probabilistic cohort stratified by age (7-19 years) and by conglomerates (schools in Asunción, Central and Caaguazú). Size sample: 2.300 subjects. A 24 hours reminder used for repeat samples. Measurement of weight and heigth according to international standards (WHO 2007). Energy requirements FAO/UN 2004/INAN. MSP y BS Analysis by ANOVA and T Test. Significance: $\mathrm{p}<0.05$.

Results: Total of 2.300 subjects ( 7 to 19 years). Median 11 years. Nutritional status: Adequate $54,5 \%$ $(\mathrm{N}=1.247)$. Overweight $27 \%(617)$ and Obesity $18,5 \%$ (423). The pattern of beverages consumption was: Volume. Median $1950 \mathrm{ml}$ (RQI 1450-2600): Water $766 \mathrm{ml}$ (IQR 491-1191); Milk and derivatives: 362 (IQR 255-471), Infusions 200 (IQR 141-450), Natural juices: 425 (IQR 300-600), Artificial juices 300 (IQR 200-500), Nectar 200 (IQR 200-350), Carbonate beverages 416 (IQR 300-616). $\%$ Adequate consumption of water according to age: $18.4 \%$. Adequate consumption of milk and derivatives: $7.5 \%$, Carbonate beverages consumption: $85 \%$, Nectar $18 \%$, artificial beverages: 50 $\%$. Calories/day from sugared beverages: $413 \mathrm{Cal} / \mathrm{day}$ as average, which corresponds to $28 \%$ of the energy requirement by age and sex.

Conclusion: The consumption pattern of these beverages in children and adolescent of our country is characterized by a less consumption of dairy products and more consumption of sugared beverages. The prevalence of malnutrition by excess is high in this group of school age children.

ISOLATED CONGENITAL HEART DE
HOSPITAL OF CONCEPCION, CHILE

Álvarez $\mathrm{A}^{1}$, Inzunza $\mathrm{C}^{1}$, Quiroz $\mathrm{V}^{1}$, Romero $\mathrm{A}^{1}$, Henríquez $\mathrm{I}^{1}$, Pérez $\mathrm{G}^{1}$

${ }^{1}$ Hospital Guillermo Grant Benavente Concepcion, Chile

Background: Congenital heart disease represents the most common congenital malformations, with an incidence of 8-10 per 1000 live births.

Objective: to describe our experience in prenatal diagnosis of congenital cardiac malformations structurally isolated in our hospital.

Methods: retrospective study of fetal echocardiograms diagnosed with congenital heart disease conducted between January 2013 and August 2016, the fetal exploration unit at the Hospital Regional de Concepción, Chile. We included all cases with isolated congenital heart disease, excluding those that were part of another malformative complex.

Results: During the study period 502 fetal echocardiograms were performed. The average age of the mother was 29 years (range: $15-45$ years), the mean gestational age was performed the test was 30 weeks (range 20-40 weeks). 167 (33\%) had a congenital heart defect, of these $52(10 \%)$ were part of a complex malformation; 115 (23\%) were isolated congenital heart disease. The main congenital heart defects were interventricular communication detected 35 (21\% of all congenital heart disease), followed by the common atrium ventricular channel 8 (4.8\%), hypertrophic cardiomyopathy $11(6.6 \%)$, hypoplastic left ventricle $6(3.6 \%)$, transposition of the great vessels $4(2.4 \%)$, Tetralogy of Fallot $3(1.8 \%)$, double outlet right ventricle $6(3.6 \%)$, aortic coarctation $2(1.2 \%)$ syndrome, cardiac tumor $2(1.2 \%)$, pulmonary atresia with ventricular septal $1(0.6 \%)$, aneurysm of the right ventricle $1(0.6 \%)$, atresia of the tricuspid $1(0.6 \%)$, single ventricle $1(0.6 \%)$, stenosis pulmonary valve (0.6\%), cardiac arrhythmia $12(7.1 \%)$ and other cardiac defects $21(12.6 \%)$.

Conclusion: The most common congenital heart diseases were the interventricular communication, followed by hypertrophic cardiomyopathy, common atrioventricular canal, hypoplastic left heart syndrome and arrhythmias. Prenatal diagnosis of congenital heart disease, given the impact on the survival of the newborn, should be an important objective search prenatal ultrasound. 


\section{0}

VENTILATOR-INDUCED SYSTEMIC INFLAMMATION AMONG VERY PRETERM NEWBORNS

Cerutti $\mathrm{M}^{1}$, Canello $\mathrm{P}^{1}$, Rizzotti $\mathrm{A}^{1}$, Tapia $\mathrm{T}^{1}$, Cuestas $\mathrm{E}^{\mathrm{1}}$

${ }^{1}$ Hospital Privado Universitario de Córdoba, Argentina

Background: Little evidence is available to document that mechanical ventilation is an antecedent of systemic inflammation in very preterm newborns (VPN).

Objective: In order to explore the relationship between the mechanical ventilation and systemic inflammation during the first week after birth, we hypothesized that ventilated VPN compared with non-ventilated VPN were more likely to have more elevated C-reactive protein blood concentrations.

Methods: Very preterm infants with gestational age $\leq 30$ weeks and a birth weight $\leq 1500 \mathrm{~g}$, born at the Hospital Privado Universitario de Córdoba between 2010 and 2015 were included. Exclusion criteria were great malformations, congenital infections, neonatal sepsis, chroriamnionitis or resuscitation in the delivery room. Blood samples for CRP were collected at day 1, 3 and 7 of postnatal life. Differences between medians were analyzed by Mann-Whitney test.

Results: 101 infants were included. Median CRP increases significantly in day 3 and day 7 ( 0.08 vs $0.06 \mathrm{mg} / \mathrm{dL}, \mathrm{p}<0.005$ and $0.08 \mathrm{vs} 0.05 \mathrm{mg} / \mathrm{dL}, \mathrm{p}<0.001)$ in ventilated infants compared with nonventilated infants. There was no difference at $1^{\text {st }}$ day of life $(0.06 \mathrm{vs} 0.06 \mathrm{mg} / \mathrm{dL}, \mathrm{p}=0.376)$ between the both groups.

Conclusion: These findings suggest that ventilated patients are more likely to be accompanied by high concentrations of CRP than non-ventilated patients. The systemic inflammation in response to mechanical ventilation may lead to ventilator induced lung injury.

\section{1}

\section{CLINICAL PHARMACOKINETIC SERVICE: PERFORMANCE EVALUATION OF THERAPEUTIC} OPTIMIZATION OF VANCOMYCIN AT A PEDIATRIC HOSPITAL

Cáceres Guido $\mathrm{P}^{1}$, Licciardone $\mathrm{N}^{1}$, Ferreyra $\mathrm{O}^{1}$, Pájaro González $\mathrm{Y}^{2}$, Schaiquevich $\mathrm{P}^{1}$

${ }^{1}$ Hospital de Pediatría Garrahan, Buenos Aires, Argentina; ${ }^{2}$ Atlantico University, Colombia

Background: Optimization of vancomycin therapy is based on the analysis of the pre-dose serum concentrations (trough or $\mathrm{C}$ ), individualizing their dosages to reduce the risk of toxicity, loss of efficiency and generation of bacterial resistance.

Objective: To evaluate the performance of the pharmacotherapy individualization service of vancomycin in inpatients at a pediatric tertiary hospital (Buenos Aires, Argentina).

Methods: Retrospective study. Individualized treatments with vancomycin were based on clinical interventions/consultations using the MM-USC*Pack program, in inpatient children (June/2011 June/2016). Recorded data: age, sex, weight, height, serum creatinine, $\mathrm{C} 0$, and initial and final dosage regimen. C0 reference therapeutic range: 5 to $20 \mu \mathrm{g} / \mathrm{ml}$. The root mean square error (RMSE) and the correlation coefficient $\left(\mathrm{R}^{2}\right)$ between the predicted and observed $\mathrm{C} 0$ was calculated. Results: 91 pharmacotherapeutic interventions in 85 patients were included; male: 66\%; age (mean, $\mathrm{SE}): 3.6 \pm 4.74$ years. Mean (SE) dosage pre and post dosage individualization were $44 \pm 14.01 \mathrm{mg}$ $\mathrm{kg} /$ day and $49 \pm 22.0 \mathrm{mg} / \mathrm{kg} /$ day respectively. $96.7 \%$ of the pharmacotherapeutic suggestions were accepted by the treating physician. The RMSE and R2 was 3.5 and 0.59 , respectively. A total of $74 \%$ of the suggestions of individualized regimens were able to adjust to serum concentrations within $\mathrm{C} 0$ therapeutic range.

Conclusion: A moderate correlation between predicted and observed $\mathrm{C} 0$ was observed along with an acceptable RMSE. The percentage of adjustments that met the therapeutic range allowed us to assume that the provision of pharmacokinetics base dosage service provides trustworthy pharmacotherapeutic suggestions, which are almost always accepted. The observed variability indicates the necessity of close monitoring of the different variables that can influence the calculation of adjustment of vancomycin pharmacotherapy regimen.

\section{2}

IODINE INTAKE IN PREGNANT WOMEN ATTENDING PUBLIC HEALTH SERVICES IN PARAGUAY Sánchez Bernal $\mathrm{S}^{1}$, Morínigo $\mathrm{G}^{1}$, Acosta $\mathrm{J}^{1}$, Masi $\mathrm{C}^{1}$, Galeano $\mathrm{M}^{1}$, Ayala $\mathrm{C}^{1}$, Coronel $\mathrm{J}^{1}$, Barreto $\mathrm{P}^{1}$, Mendoza $\mathrm{L}^{1}$

${ }^{1}$ Instituto Nacional de Alimentación y Nutrición-INAN, Ministerio de Salud Pública y Bienestar Social, Paraguay

Background: Iodine is required to produce thyroids hormones, which are involved in brain development of the fetus during pregnancy. Urinary excretion of iodine allows the estimation of its dietary intake.

Objective: Determine iodine intake through urinary excretion in pregnant women attending public health services in Paraguay.

Methods: Cross-sectional and descriptive study with 859 pregnant women whose iodine levels from isolated urine samples (morning shot) were determined by ammonium persulfate method (Sandell Kolthoff reaction, modified from Pino and Dunn) and evaluated according to WHO / UNICEF / ICCIDD criteria.

Results: The average age was $23.6 \pm 6.3 \mathrm{DE}$ (14-44 years old). The median urinary iodine level was $228 \mu \mathrm{g} / \mathrm{L}(40-771 \mu \mathrm{g} / \mathrm{L})$. Iodine levels were deficient $(<150 \mu \mathrm{g} / \mathrm{L})$ in $25 \%$ of the samples. adequate $(150-249 \mu \mathrm{g} / \mathrm{L})$ in $31 \%$. above adequate levels $(250-499 \mu \mathrm{g} / \mathrm{L})$ in $39 \%$ and excessive $(\geq 500 \mu \mathrm{g} / \mathrm{L})$ in $5 \%$. Urine excretion was lower in $\geq 25$ weeks pregnant women $(n=288)$ than in $\leq 12$ weeks $(n=245)$ and 13-24 weeks pregnant women ( $\mathrm{n}=326$ ) with average values of $233.3 \mathrm{vs} 286.1 \mathrm{vs} 260.0 \mu \mathrm{g} / \mathrm{L}$ respectively (ANOVA for independent samples, $\mathrm{p}=0.007$ ). Deficiency was lower in women who were less than 12 weeks pregnant ( $18 \%$ vs $28 \%, \div 2 \mathrm{p}=0.02$ ).

Conclusion: one of each four pregnant women has an insufficient iodine intake according to urine excretion. The proportion of iodine deficiency is lower among pregnant women in their first trimester and average iodine excretion is lower in pregnant women in their third trimester.
13

RELATIONSHIP BETWEEN ACADEMIC PERFORMANCE IN HIGH SCHOOL AND CONSUMPTION OF SUGAR-SWEETENED DRINKS, DAIRY PRODUCTS AND SATURATED FATS IN CHILEAN ADOLESCENTS

Loeff T ${ }^{1}$, Correa-Burrows $\mathrm{P}^{1}$, Curi $\mathrm{K}^{1}$, Blanco $\mathrm{E}^{2}$, Gahagan $\mathrm{S}^{2}$, Burrows $\mathrm{R}^{1}$

${ }^{1}$ Institute of Nutrition and Food Technology, University of Chile, Santiago, Chile; Division of Child Development and Community Health, University of California San Diego (USA)

Background: A diet high in saturated fat and refined carbohydrates is very common among Chilean school-age children. These macronutrients negatively impact learning and memory processes dependent on the hippocampus. In contrast, the consumption of dairy products has been positively associated with cognitive functioning.

Objective: To study the relationship between school performance in secondary education and consumption of dairy products, sugary drinks and high-fat foods in Chilean adolescents.

Methods: Sample of $n=493$ teenagers aged $16-17$ (50\% female). Food intake was assessed with validated food frequency questionnaire. Weekly consumption of sugary drinks, dairy products and high fat foods was recorded. Daily intake of foods was estimated. High school grade-point average (GPA) was obtained from public records and transformed into score (210-825 scale), according to the Ministry of Education (Chile). To explore the association between daily intake of dairy products, sugary drinks and high fat foods with academic performance, linear regression analysis was used, adjusting for sex, nutritional status and parental education.

Results: We found a negative association of high school GPA with daily consumption of sugar sweetened beverages $(\beta=-19.1, P=0.003)$ and high fat food items $(\beta=-8.1, P=0.001)$. Conversely, the association of GPA with daily consumption of dairy products was positive and significant ( $\beta=18.5, P=0.003)$. Conclusion: Consumption of high fat/high sugar foods affects academic performance, resulting in a lower high school GPA. This study confirms previous evidence linking the so-called Western diet with neurobiological changes in the hippocampus that impair cognitive function and lead to lower school performance.

Funding: NHBLI HL088530 and PAI-79140003.

14

PRESENCE OF FUNGI AND AFLATOXINS IN YERBA MATE IN PARAGUAY

Mendoza $L^{1}$, Peralta $\mathrm{I}^{1}$, Arrúa $\mathrm{A}^{1}$, Echeverria $\mathrm{P}^{1}$, Benitez $\mathrm{A}^{1}$, Ulke $\mathrm{M}^{1}$, Sanchez Bernal $\mathrm{S}^{1}$, Giménez $\mathrm{E}^{1}$, Dominguez $\mathrm{R}^{1}$, Arias $\mathrm{M}^{1}$, Avalos $\mathrm{C}^{1}$, Ferreira $\mathrm{F}^{1}$, Castro $\mathrm{N}^{1}$, Pizarro $\mathrm{F}^{1}$.

${ }^{1}$ Centro Multidisciplinario de Investigaciones Tecnológicas, Universidad Nacional de Asunción, Paraguay

Background: The consumption of yerba mate (Ilex paraguariensises) is approximately $2.6 \mathrm{~kg} / \mathrm{year} /$ inhabitant in Paraguay. Because this product has favorable characteristics for fungi growth, it is necessary to determine the types and quantities of fungi species, since they can produce aflatoxins, which are related to certain types of neoplasia.

Objective: To evaluate the presence of fungal species and aflatoxin in packaged yerba mate from Paraguay.

Methods: Five samples were taken of each of the 39 brands of yerba mate with valid formal registration (Codex methodologyCAC/GL 50-2004). The 195 samples were cultivated in PDA (potato dextrose agar). Identification of fungal species was performed by counting and purification of colonies. The presence of Mycotoxins belonging to the genus of aflatoxins (types B1, B2, G1 and G2) was also determined by HPLC, and evaluated according the Paraguayan Standard (PN 3500193), also used for counting fungi and yeasts.

Results: Fungal colonies were identified with macro and micro morphological characteristics of Aspergillus sp.: flavi, nigri, circumdati, fumigati, wentii, usti, versicolor, nidulans. Some fungi not belonging to the genus Aspergillus were also identified: Penicillium, Fusarium, Rizophus, Curvularia, Chalara and Chalaropsis. Fifteen from 39 brands of yerba mate showed high levels of fungi and yeast contamination ( $>1800 \mathrm{CFU} / \mathrm{g}$, NP 3500193). For aflatoxins, 37/39 brands showed higher levels of $\mathrm{G} 1$ ( $>2.6 \mathrm{mg} / \mathrm{kg}, \mathrm{NP} 3500193), 4$ out of 39 for type B1 (>1.9 mg / kg, NP 3500193), 1 out of 39 for B2 $(>2.4 \mathrm{mg} / \mathrm{kg}$, NP 3500193), 2/39 for aflatoxin G2 (>2.4 mg/kg, NP 3500193) type.

Conclusion: Fungi belonging to the Aspergillus genus were identified in all samples collected, both producing and not producing aflatoxins, in addition to other fungal species. Moreover, Aflatoxin G1 levels were found in 9 out of 10 samples, showing the urgency of working on good agricultural and manufacturing practices.

\section{5}

COMPARISON OF HEAD CIRCUMFERENCE OF NEWBORNS FROM JUJUY (ARGENTINA) WITH THE INTERGROWTH-21ST SIZE AT BIRTH STANDARD

Martínez J ${ }^{1}$, Alfaro $E^{1}$, Grandi $C^{2}$, Dipierri J ${ }^{1}$

${ }^{1}$ Instituto de Ecorregiones Andinas (INECOA), Jujuy, Argentina. ${ }^{2}$ Facultad de Medicina de Ribeirão Preto. Univ. San Pablo, Brasil

Background: The increased rate since mid-2015 of microcephaly cases associated with Zika virus in Brazil has determined that WHO declares that this epidemic is an international public health emergency (PHEIC). An emerging problem is the anthropometric diagnosis of microcephaly. It requires deeper knowledge about the cutoffs and references and / or standards to measure the head circumference (HC) and diagnose suspected cases of microcephaly.

Objective: the aim of this study was to compare the distribution of HC by sex and gestational age (GA) of the newborn population of the province of Jujuy, Argentina, with the recently introduced into clinical practice Intergrowth-21st standards.

Methods: The data source was the Perinatal Informatics System (SIP, PHAO/WHO) in the province of Jujuy (2008-2013). Inclusion criteria were GA between 24 and 42 weeks and birth weight more than 500 grams. Exclusion criteria were major and minor malformations, toxoplasmosis and stillbirth. The mean and SD of HC was calculated by gestational age and sex. The differences with the Intergrowth-21st standard were calculated with the Student $t$ test. 


\section{Abstracts}

Results: The sample was constituted by 46,146 newborns (22,799 girls and 23,347 boys). Newborns from Jujuy presented in both sexes a higher $\mathrm{HC}$ compared with the Intergrowth-21st standard on all GA, with statistically significant differences in almost all except 24th, 25th, 27th, 28th and 29th weeks in girls and in the 25 th week in boys, attributable to small sample size.

Conclusion: The application of Intergrowth-21st standard to Jujuy population may overestimate the suspected cases of microcephaly. New epidemiological studies to assess the specificity and sensitivity of other selection criteria, standards and / or references applicable to the detection of suspected cases of microcephaly are required, such as the recently published recommendations of the WHO (WHO / ZIKV / MOC / 16.3 / Rev3).

16

BODY COMPOSITION OF CHILEAN INFANTS UNDER 4 MONTHS OF AGE: A DESCRIPTIVE STUDY

Prieto $^{1}$ L, Weisstaub $\mathrm{G}^{1}$, Uauy R ${ }^{1}$, Corvalán $\mathrm{C}^{1}$

${ }^{1}$ Instituto de Nutrición y Tecnología de Alimentos, Universidad de Chile

Background: Nutrition and body composition in the first months of infant's life determine the future risk of developing chronic diseases, so it is important to generate local information that can serve as a reference to monitor healthy growth.
Objective: To describe body composition (fat mass (FM-kg-) and fat-free mass (FFM-kg-)) according to type of feeding (exclusive breastfeeding (EBF) or exclusive formula (EF)).

Methods: 99 infants ( $44.4 \%$ female) Chileans, term without pathology, less 4 months old, trained nutritionists measured weight and length, body mass index (BMI: weight / height) was calculated and Z scores according to WHO 2005 (ANTHRO). Body composition was measured with air displacement plethysmography (PEA POD ${ }^{\circ}$ ) and by food questionnaire was classified as EBF if breastfeeding received without other food or FE, if the formula received without other food. Wilcoxon test was used to assess significance of differences by type of food. This study was approved by the ethics committee of the University of Chile-INTA.

Results: On average, infants grew below standard in size (HAZ-0.55) but higher in BMI (BAZ 0.31 ), with no differences by sex ( $p>0.05$ ). The average was 1.4 FM no differences by sex, while men were slightly higher FFM (4.6 vs 4.2). Both the FM and FFM were higher at 2 and 3 months old (60-89d: FM 1.25 FFM 4.27; 90-119d: FM 1.78 FFM 4.86), but the increase was proportionately higher in fat $(23 \%$ to $27 \%, \mathrm{p}<0.001)$. There were no differences according to type of feeding $(\mathrm{p}>$ 0.05).

Conclusion: Significant changes are observed in body composition between 2 and 3 months, with no differences by sex or type of food. Increasing infant's evaluation and its longitudinal follow-up will confirm these observations. 